Contato

Rua Duque Estrada, 31 - apto. 502 22451-090 - Rio de Janeiro - R lucianoraposo@uol.com.br

\section{A LINGUAGEM DA EMBRIAGUEZ: CACHAÇA E ÁLCOOL NO VOCABULÁRIO POLITICO DAS REBELIÕES NA AMÉRICA PORTUGUESA*}

\section{Luciano Raposo de Almeida Figueiredo*}

Universidade Federal Fluminense

Rio de Janeiro - Rio de Janeiro - Brasil

\title{
Resumo
}

Semelhante ao que se passa na Europa durante a Idade Moderna, foi frequente no Brasil colônia a atribuição de embriaguez aos grupos que promoveram protestos e rebeliões. O recurso discursivo pretendia desqualificar a legitimidade das reivindicações ao plasmar no imaginário político os rebeldes e a bebida alcóolica consumida por escravos.

\section{Palavras-chave}

Bebidas alcóolicas - cachaça - revoltas - Brasil colônia.

Agradeço aos professores Renato Venâncio e João Azevedo Fernandes (in memorian) as sugestões e críticas que ofereceram a este texto, cuja versão original foi apresentada no IV Colóquio Internacional (IN)TOLERÂNCIA Religião, raça e política no mundo ibérico do Antigo Regime realizado na UFF em setembro de 2011 pelo Núcleo da Companhia das Índias. A pesquisa foi desenvolvida no âmbito do projeto de bolsa de produtividade do CNPq "Tradições intelectuais e lutas políticas na América portuguesa moderna, séculos XVI-XVIII".

** Graduação em História na PUC-RJ. Mestrado e doutorado em História Social na Universidade de São Paulo. Professor do Instituto de História da Universidade Federal Fluminense. Pesquisador do CNPq. 


\section{THE LANGUAGE OF DRUNKENNESS: \\ CACHACCA AND ALCOHOL IN}

\section{THE POLITICAL}

VOCABULARY

DURING THE

AMERICAN

PORTUGUESE

REBELLIONS

Rua Duque Estrada, 31 - apto. 502

Contact

22451-090 - Rio de Janeiro - RJ lucianoraposo@uol.com.br

Luciano Raposo de Almeida Figueiredo

Universidade Federal Fluminense

Rio de Janeiro - Rio de Janeiro - Brazil

\section{Abstract}

Similarly to events occurring in Europe during the modern age, drunkenness was often attributed to those groups promoting the protests and rebellions in colonial Brazil. The rhetoric intended to downplay legitimate claims by clouding the political imagination with images of rebels and drunken slaves.

\section{Keywords}

Spirits - cachaça - rebellions - colonial Brazil. 
Aqueles eram dias de muita bebida e a maioria dos homens bebia além da conta.

Charles Dickens, Um conto de duas cidades.

Sérgio Buarque de Holanda entendia de cachaça. A revelação aparece perdida no meio de uma entrevista publicada em 1977 no Folhetim, suplemento dominical de cultura do jornal Folha de S.Paulo. ${ }^{1}$ Colhida por vários jornalistas escalados para escutar o notável historiador - dentre os quais Tarso de Castro e Paulo Duarte - o diálogo corria animado entre os participantes, seguindo como uma nau sem rumo, saltando da noção do "homem cordial" à censura do regime militar. Em certo momento a conversa estaciona em um assunto que eletrizou o ambiente: a cachaça. Todos ali pareciam dominar plenamente o tema, deitando histórias as mais divertidas. Os comentários brotavam sem parar em uma atmosfera cuja empolgação crescia. Quando mencionam o sucesso da bebida em Paris, Sérgio Buarque, que até ali pouco conseguira falar, pede a palavra (nessa antológica entrevista os jornalistas falam mais do que o entrevistado). Demonstrando que apreciava a história da bebida conta uma das anedotas que conhecia a propósito, fazendo questão de registrar que, também ele, possuía "muita experiência pessoal" no assunto. ${ }^{2}$

Na Prússia, em pleno século XIX, narra Sérgio, o ministro do Brasil Joaquim Maria do Amaral, durante reunião com Bismarck, foi interpelado por este que, quebrando o protocolo, indagou: "qual a bebida que tem no Brasil?". Pego de surpresa, o nosso ministro responde prontamente "Bebe-se cerveja, vinho, conhaque", ao que o primeiro-ministro, não satisfeito, retruca, "Bom, mas tudo isso é bebida internacional, e a bebida própria do Brasil?". "Não tem", reage o outro. Diante da atitude de incredulidade do prussiano acaba por revelar com relutância, "Bom... tem uma bebida que só os escravos é que tomam, os negros é que tomam". A seguir, espantado fica Joaquim quando Bismark pede ao diplomata: "Eu gostaria de tomar isso" (o que na boca de um prussiano deve ter soado como uma ordem). O brasileiro encomenda então uma pinga de excelente qualidade que seria prontamente entregue.

\footnotetext{
1 MARTINS, Renato (org.). Sergio Buarque de Holanda. Encontros. Rio de Janeiro: Azougue, 2009, p. 96-135.

2 A experiência profissional de Sérgio Buarque de Holanda com relação ao tema pode ser ilustrada com base em sua obra, pois, em Caminhos e fronteiras, analisa o uso medicinal da aguardente e, em Monções, menciona seu papel econômico ao lado da expansão dos engenhos.
} 
Luciano Raposo de Almeida Figueiredo

A linguagem da embriaguez: cachaça e álcool no vocabulário político das rebeliöes na América portuguesa

Na reunião seguinte, Bismarck se aproxima do brasileiro e vai direto ao assunto: "Olha aqui! Se os pretos bebem aquilo, por que os brancos não bebem?".

Não faz parte das intenções desse artigo responder ao "Napoleão da Alemanha", apresentado então à nossa autêntica cachaça, apreciador que era de uma boa schnapps, como os alemães chamam os destilados mais vigorosos. Nosso propósito é seguir em um terreno bem distinto, ainda que associado à perspectiva que a anedota sugere quando aproxima o consumo da aguardente às camadas populares, aos "pretos" e aos "escravos", que o treino diplomático do ministro brasileiro, aflito em passar uma impressão civilizada do país que representava, parecia querer esconder diante da insistente curiosidade do europeu.

O desconforto do diplomata evocava a persistente desqualificação que cerca a bebida desde tempos remotos, quando o consumo imoderado da cachaça no Brasil esteve associado a indisciplina, violência e imoralidade, especialmente das camadas sociais mais baixas.

Nosso tema contudo trata de uma outra forma capaz de desabonar o uso da aguardente. Nos discursos das autoridades portuguesas e luso-brasileiras atuantes na época colonial emergiram enunciados em que as atitudes desafiadoras durante as mobilizações populares foram associadas ao consumo da cachaça pelos rebeldes. E aqui não importa se estes haviam de fato consumido ou não a bebida enquanto protestavam.

As lutas políticas no Novo Mundo integram o mesmo processo que se verifica ao longo dos séculos XVII e XVIII quando se aprofundam protestos e sedições no mundo moderno europeu perante os quais se adotaria uma posição de maior rigor moral e ético. ${ }^{4}$ No plano da linguagem, emergem na América tópicas que associam identidades locais e gentílicas a certas transgressões que sustentam ações repressivas amparadas no universo de tradições políticas.

\footnotetext{
MARTINS, Renato (org.). Sergio Buarque de Holanda. Encontros, op. cit., 2009, p. 119.

${ }^{4}$ Servindo de referência para o presente artigo estão alguns estudos notáveis que inovaram as interpretações sobre o consumo etílico e as tensões sociais na América portuguesa: FERNANDES, João Azevedo. Selvagens bebedeiras: álcool, embriaguez e contatos culturais no Brasil colonial (séculos XVI-XVII). São Paulo: Alameda, 2011; CARNEIRO, Henrique. Bebida, abstinência e temperança na história antiga e moderna. São Paulo: Editora Senac, 2010; AVELAR, Lucas Endrigo Brunozi. A moderação em excesso: estudo sobre a história das bebidas na sociedade colonial. Dissertação de mestrado em História, USP, 2010; e VENÂNCIO, Renato Pinto E CARNEIRO, Henrique (org.). Álcool e drogas na história do Brasil. Belo Horizonte - São Paulo: PUC Minas e Alameda, 2005.
} 


\section{Indigestões da cachaça}

Não raro, no Novo e no Velho Mundo, autoridades ameaçadas pelos protestos populares apodariam os rebeldes com uma linguagem comum da embriaguez. ${ }^{5}$ A suspeita de consumo descontrolado de álcool serviu para sublinhar o desordenamento na conduta política dos súditos.

O vocabulário pretendia nitidamente desqualificar o direito à resistência e a relevância das muitas reclamações que conduziam à conflagração, associando-as à intemperança com a bebida preferida dos moradores mais humildes da colônia, escravos, homens livres e pobres. A referência à cachaça se converte em mecanismo para estigmatizar e reprovar socialmente grupos populares que entram na cena política colonial.

Quando da derrota portuguesa em Porto Calvo contra os holandeses (1637) Antônio Felipe Camarão, que liderou os índios na reação aos ocupantes, mereceu caracterização heroica por suas empresas militares, sob o esforço de construção de sua memória. ${ }^{6}$ O governador da capitania, no entanto, pensava diferente, pronunciando-se contrário aos hábitos de Camarão que "não fez neste dia mais que se emborrachar com aguardente".7 Julgamentos semelhantes escutavam-se nas contestações portuguesas, como na revolta de Évora em 1637. Os motins com presença popular nos quais a autoridade régia era confrontada, segundo aparece em um pasquim, "mais pareciam bebedices, que parvoices". ${ }^{8}$

Os rebeldes pernambucanos e lusos não foram os únicos a demonstrar afeição à bebida local. Conta-se que no Maranhão, em 1674, quando conspirava contra os jesuítas e a Companhia de Comércio, um dos irmãos da família Beckman, simulando a celebração de uma missa, vestiu trajes sacerdotais

\footnotetext{
${ }^{5}$ O papel do álcool como elemento de desestabilização política sob a condição colonial foi sugerido por SCARANO, Julita. Bebida alcoólica e sociedade colonial. In: JANCSÓ, István \& KANTOR, Iris (org.). Festa: Cultura e sociabilidade na América portuguesa. São Paulo: Hucitec; Editora da Universidade de São Paulo; Fapesp; Imprensa, 2001, p. 480.

${ }^{6}$ RAMINELLI, Ronald. Honras e malogros: trajetória da família Camarão, 1630-1730. In: VAINFAS, Ronaldo \& MONTEIRO, Rodrigo Bentes (org.). Império de várias faces. Relações de poder no mundo ibérico da Época Moderna. São Paulo: Editora Alameda, 2009, p. 175-191.

7 RAMINELLI, Ronald. Honras e malogros: trajetória da família Camarão, 1630-1730, op. cit., 2009, p. 175-191, p. 179.

8 OLIVEIRA, António de. Poder e oposição política em Portugal no período filipino, 1580-1640. Lisboa: Difel, 1991, p. 212.
} 
Luciano Raposo de Almeida Figueiredo A linguagem da embriaguez: cachaça e álcool no vocabulário político das rebeliōes na América portuguesa

e usou a cachaça no lugar do vinho.9 O consumo generoso de álcool durante a revolta de Beckman foi também denunciado por um cronista sob o crivo da desqualificação da parte de quem observa, e teme. Alguns anos passados, Francisco Teixeira de Moraes narrou, em 1692, aqueles dias agitados. Autor erudito, ao ilustrar os movimentos da multidão (como uma "descabeçada hidra") parece descrever um festim orgiástico de Roma antiga:

ao som de guitarras e pandeiros, dançando e cantando em sumo grau, frouxos e remissos nas paixões da alma, não deixando de fazer suas visitas às tavernas e casas dos moradores que eles conheciam, que pelos ter gratos e placáveis os esperam com os sacrifícios de Baco prevenido. ${ }^{10}$

O recurso de associar os excessos e a conduta reprovável dos rebeldes ao consumo de álcool não é exclusivo da tradição católica ibérica. A mesma condenação moral integra os esforços da desqualificação empregada pelos ingleses quando se referem a uma de suas rebeliões coloniais. Diversas fontes que narram a revolta comandada pelo homem de fronteira, Nathaniel Bacon, na Virginia, em 1676, mencionam seu estado de bebedeira quando decide, contrariando abertamente a proibição do governador, atacar os índios, atitude que iria levar a colônia à conflagração. ${ }^{11}$

Gregório de Matos foi outro que não perdeu a oportunidade de aplicar a mácula do álcool e da embriaguez a rebeldes, sob o império da sátira, também capaz de condenar condutas. Enquanto padecia o degredo em Angola, o poeta se vê repentinamente dragado por um motim militar que sacode a cidade de Luanda em 1694. A soldadesca, aproveitando-se da chegada de um novo governador, reage contra o rebaixamento dos soldos diante de uma manobra para a mudança do padrão monetário, trocando-se os libongos ${ }^{12}$ por cobre. O terço da infantaria, artilharia e cavalaria se amotina, ocupa

\footnotetext{
9 “Um sacrilégio!", escreveu Luiz Mott, autor de Cotidiano e vivência religiosa: entre a capela e o calundu. In: SOUZA, Laura de Mello e (org.). História da vida privada no Brasil: cotidiano e vida privada na América portuguesa, vol. 1. São Paulo: Companhia das Letras, 1997, p. 167-168.

${ }^{10}$ MORAES, Francisco Teixeira de. Relação histórica e política dos tumultos que sucederam na cidade de S. Luiz do Maranhão .... [1692]. RIHGB, tomo 40, $1^{\text {a }}$ parte, p. 340.

${ }^{11}$ HASKELL, A. B. "The affections of the people": ideology and the politics of State building in colonial Virginia, 1607-1754. Baltimore: Johns Hopkins University, 2004, p. 226.

${ }^{12}$ Libongos eram panos utilizados como moeda na África centro ocidental. "Panos de ráfia conhecidos também por panos sambue, panos soka". Eram fabricados em Luango e exportados para toda a África centro ocidental, servindo como meio de troca. PARREIRA, Adriano. Dicionário glossográfico e toponímico da documentação sobre Angola. Séculos XV-XVII. Lisboa: Editorial Estampa, 1990, p. 64.
} 
uma das principais regiões da cidade e encaminha sua pauta de reivindicações ao soberano. Para dar forma às capitulações recorrem à ajuda do letrado Gregório de Matos, retirado de sua casa pela turba e instado a participar, contra sua vontade, segundo consta.

Além de soldados havia ali o dedo dos comerciantes, especialmente os importadores da jeribita, como a aguardente de cana era conhecida na África, cuja importação estava proibida desde 1679.13 Apesar da aceitação dos pedidos e aparente sucesso dos rebeldes, o governador Henrique Jacques de Magalhães reage, prende pelo menos dez líderes e fuzila sete sem clemência. ${ }^{14}$

Gregório, protegido do governador, escapa e, à sua maneira, homenageia o episódio e a terra que logo deixaria, reavendo a tópica da ebriedade ajustada à paisagem africana. No poema Que fez o autor em Angola no levantamento dos soldados, ${ }^{15}$ constrói a figura satírica do "rei dos jeribiteiros" ou, ainda, a do "soba dos borrachos", título que atribui ao soldado que se fez líder:

\author{
Angola é terra de pretos \\ mas por vida de Gonçalo, \\ que o melhor do mundo é Angola, \\ e o melhor de Angola os trapos. \\ (...) \\ Houve o motinar-se o Terço \\ e de ponto em branco armado \\ na praia de Nazareth, \\ por nós em sítio versado. \\ Houve que Luis Fernandez \\ foi entonces aclamado \\ por rei dos giribiteiros, \\ ou por soba dos borrachos.
}

${ }^{15}$ ALENCASTRO, Luiz Felipe de. O trato dos viventes. Formação do Brasil no Atlântico Sul, séculos XVI $e$ XVII. São Paulo: Companhia das Letras, 2000, especialmente "os tumultos dos jeribiteiros", p. 314-323. CALMON, Pedro. A vida espantosa de Gregório de Matos. Rio de Janeiro: José Olympio, 1983, p. 186-189.

${ }^{14}$ ALENCASTRO, Luiz Felipe de. O trato dos viventes. Formação do Brasil no Atlântico Sul, séculos XVI e XVII, op. cit., , especialmente "os tumultos dos jeribiteiros", p. 314-323. CALMON, Pedro. A vida espantosa de Gregório de Matos, op. cit., 1983, p. 186-189.

${ }^{15}$ PERES, Fernando da Rocha. Gregório de Mattos e Guerra em Angola. Afro-Ásia, 6, 1968, p. 1740; CALMON, Pedro. A vida espantosa de Gregório de Matos, op. cit., 1983, p. 186-189. 
Luciano Raposo de Almeida Figueiredo

A linguagem da embriaguez: cachaça e álcool no vocabulário político das rebeliões na América portuguesa

No século seguinte, nos conflitos que ocorreram no Brasil, a tópica da embriaguez permaneceria. Os furores sertanejos que varrem o sertão de Minas Gerais, Bahia e Pernambuco às bordas do rio São Francisco em 173637 reúnem potentados e uma massa de mamelucos, indígenas, lavradores pobres, escravos e forros, mulatos, negros e mulheres contrários à cobrança do quinto sobre o ouro (que ali não se extraía). Tomou corpo o grito de "vivas do Povo e morram traidores" durante a onda de ataques a fazendas e aos arraiais nesses protestos que fugiam à regra das revoltas dirigidas pela elite, quando chegam a organizar um autogoverno cujas funções foram ocupadas por pessoas dos baixos estratos sociais. ${ }^{16}$

Dentre os variados julgamentos oferecidos sobre os rebeldes pelas autoridades que pisaram naquela paisagem agreste, uma das narrativas a respeito do comportamento dos sublevados desdenha: "que aquilo era muita força de aguardente e que não fossem tolos que contra a ordem de El rei nosso senhor ninguém se opunha". ${ }^{17}$

Pouco tempo antes, no centro nervoso de Minas Gerais, menção semelhante à intemperança popular escapa da correspondência do governador a quem coube enfrentar um protesto em Vila Rica no ano de $1720 .^{18} \mathrm{Ali}$, escravos, artesãos e o povo da vila, mobilizados por mineradores indispostos com a notícia da chegada de Casas de Fundição que faria pesar a cobrança do direito régio do quinto sobre o ouro, agitam a cidade. O conde de Assumar, quando recebe as primeiras notícias dos tumultos, entre a desconfiança e a empáfia, tripudia da seriedade das intenções e do perigo daquela gente,

\footnotetext{
${ }^{16}$ Sobre os motins do sertão ver ANASTASIA, Carla Maria Junho. Potentados e bandidos: os motins do São Francisco. Revista do Departamento de História da UFMG, n. 9, 1989, p. 74-85; ROGRIGUES, Gefferson Ramos. No sertão, a revolta: Grupos sociais e formas de contestação na América portuguesa, Minas Gerais - 1736. Niterói-Rio de Janeiro: UFF/Departamento de História, 2009.

17 Portugal. Arquivos Nacionais/ Torre do Tombo, Livros do Brasil, livro 10, fl 204-209. Proposta e requerimento que fazem os povos das Minas Gerais, e os seus distritos a el-rei nosso senhor que deus guarde.

${ }^{18}$ Sobre a revolta de Vila Rica ver FONSECA, Alexandre Torres. A revolta de Felipe dos Santos. In: RESENDE, Maria Efigênia Lage de (coord.). História de Minas Gerais. As Minas setecentistas, vol. 1. Belo Horizonte: Companhia do Tempo; Autêntica, 2007, p. 549-566; CAMPOS, Maria Verônica Governo dos mineiros. "De como meter as Minas numa moenda e beber-lhe o caldo dourado". 1603 a 1737. Tese de mestrado de História, USP, São Paulo, 2002, p. 214-259; MATHIAS, Carlos Leonardo Kelmer. No exercício de atividades comerciais, na busca da governabilidade: d. Pedro de Almeida e sua rede de potentados nas minas do ouro durante as duas primeiras décadas do século XVIII. In: FRAGOSO, João L. R. et al. (org). Conquistadores e negociantes. Rio de Janeiro: Civilização Brasileira, 2007, p 195-222.
} 
justificando que tudo não passava de "indigestões de cachaça". ${ }^{19}$ "Indigestão" não alude aqui a problemas no estômago. Segundo vocabulário da época, publicado por Raphael Bluteau, além desse significado usual, a palavra aparecia empregada com o sentido de correção de abusos (verbete "indigestam") e ainda exprimindo "cousa confusa, posta sem ordem" (verbete "indigesto"). ${ }^{20}$ Na boca do governador, a figura denotava uma ideia de confusão motivada pela bebida, não qualquer uma, mas a bebida rude dos escravos, atualizando assim para a paisagem tensa das Minas Gerais a detratação dos movimentos políticos compostos por grupos populares.

Em uma das cartas que dispara ao rei, no dia 3 de julho, o governador parece abusar da linguagem grosseira plasmando sua narrativa à consideração que devotava à plebe. Ao descrever ao soberano um dos episódios do motim, conta que "em uma das noites um mascarado para o irritar disse que eu escrevera à câmara [mencionando] que todos os do Povo estavam bêbados, e que quando cosessem a fornada acabaria o motim, o que tal não houve". ${ }^{21}$ "Cozer a fornada" se referia, segundo dicionários de época, a quem dorme depois de beber demais. Os letrados Raphael Bluteau e Antônio de Moraes Silva, em seus dicionários (1728 e 1789, respectivamente), sublinham que se trata de termo chulo. ${ }^{22}$ A estranheza do emprego desse tipo de palavra em uma carta dirigida ao soberano, atribuída embora a um "mascarado", reforça os artifícios de desqualificação pretendidos.

Na Bahia, o mesmo tipo de associação com o consumo etílico também apareceu, desta vez na revolta do Terço Velho, regimento que vivia sempre com o pagamento em atraso, deixando os soldados em situação de miséria absoluta. ${ }^{23}$ Durante um dos protestos em 1728, o vice-rei enfrentou os sol-

\footnotetext{
${ }^{19}$ Carta do conde de Assumar a João da Silva Guimarães. Vila do Carmo, 25 de junho de 1720. Publicada em CARVALHO, Teófilo Feu de. Ementário da história de Minas; Felipe dos Santos na sedição de Vila Rica, 1720. Belo Horizonte: [s.d.], p. 54-55.

${ }^{20}$ BLUTEAU, Raphael. Vocabulario portuguez \& latino, vol. 4, p. 108. Disponível em: http://www. brasiliana.usp.br. Acesso em: 24 de janeiro de 2014.

${ }^{21}$ Carta de d. Pedro de Almeida ao rei. Vila do Carmo, 3 de julho de 1720. Biblioteca Nacional de Lisboa. Reservados. Coleção Pombalina, códice 479, fls. 97-100v.

22 BLUTEAU, Raphael. Vocabulario portuguez E latino, vol. 4, p 177; SILVA, Antônio de Moraes. Diccionario da lingua portugueza, vol. 2, p. 49. Disponíveis em: http://www.brasiliana.usp.br. Acesso em: 24 de janeiro de 2014.

${ }^{23}$ A revolta do Terço Velho ainda não mereceu estudos à luz dos novos debates. Vale lembrar, porém, COSTA, Luiz Monteiro. Na Bahia colonial. Apontamentos para a história militar da cidade do Salvador. Bahia: Livraria Progresso Ed., [s.d.] (Coleção de Estudos Brasileiros, série Marajoara, 23); PITTA, Sebastião da R. História da América portuguesa. Introdução e notas de Pedro Calmon. Belo Horizonte: Itatiaia; São Paulo: Edusp, 1976.
} 
dados amotinados e no encontro com eles teria indagado: "que bebedice ou atrevimento era aquele?". E disse, a título de conciliação, que tal ato de rebeldia só se justificava por estarem bêbados de "vinho ou aguardente" e que por isso os perdoaria se acabassem com o tumulto. ${ }^{24} \mathrm{O}$ tumulto não acaba e o grau de tolerância do governador seria ilustrado com os corpos pendurados nas forcas que se espalharam pela cidade.

O papel detrator do consumo alcoólico associado à imoralidade e desordem invadiria ainda a narrativa historiográfica. O diretor do Arquivo Público Mineiro e historiador Teófilo Feu de Carvalho, abandonando aparentemente o rigor no uso das fontes, não economiza imaginação nem tampouco estereótipos para apresentar os negros (que sequer seriam "brasileiros", ao contrário da referência que faz a paulistas e baianos) participantes da revolta de Vila Rica, no episódio da destruição da casa de Pascoal da Silva Guimarães. Teriam sido eles, escreve Teófilo, os responsáveis pelos saques e incêndios ocorridos quando da repressão ao morro do Ouro Podre, covil das lideranças rebeldes em Vila Rica. Ali os negros

regalaram-se com as bebidas e comestíveis que abundavam nas inúmeras vendas e casas de pasto (...) embriagados formaram uma verdadeira orgia, em proporções muito maiores do que as que, por anos a fio, lá existiam (...).

E conclui com entusiasmo: "Esta foi a última e, portanto a mais farta bacanal que no morro de Pascoal da Silva Guimarães ou do Ouro Podre, jamais houvera!". ${ }^{25}$

A linguagem fazendo alusão à ebriedade parece ter se consolidado nos discursos políticos também em Portugal. No Porto, em 1757, os esforços do rei em controlar o número de tabernas para proteger a qualidade do vinho da região provocou uma rebelião com larga participação popular (e, segundo alguns, provocada pela pregação de um padre bêbado) que mereceria a designação de "revolta dos borrachos". Para não fugir à regra ela seria violentamente reprimida. ${ }^{26}$

\footnotetext{
${ }^{24}$ COSTA, Luiz Monteiro da. Na Bahia colonial. Apontamentos para história militar da cidade do Salvador, op. cit., [s.d.], p. 123

${ }^{25}$ CARVAlHO, Teófilo Feu de. Ementário da história de Minas; Felipe dos Santos na sedição de Vila Rica, 1720. Belo Horizonte, [s.d.].

26 SILVA, Francisco Ribeiro da. Absolutismo esclarecido e intervenção popular. Os motins do Porto de 1757. Lisboa: Imprensa Nacional-Casa da Moeda, 1990.
} 
No último quartel do século XVIII, o discurso desqualificador mostra força e persistência na América, apesar de as ideias políticas não serem mais as mesmas que marcaram as contestações anteriores. Luís dos Santos Vilhena em sua Recopilação de notícias soteropolitanas e brasílicas emprega o mesmo tipo de tratamento ao se referir à Conjuração de 1798 na Bahia. O professor régio adjetiva os conspiradores de "malvados revoltosos que perfidamente haviam projetado a insubsistente sublevação e cruel massacre, produções tudo da ociosidade, ignorância e embriaguez".27

\section{A intemperança popular}

Os registros negativos sobre o caráter da multidão em fúria são velhos conhecidos da tradição política do pensamento moderno, especialmente na Europa, apontados por historiadores que, desde os anos 50 do século passado, escolheram as rebeliões como tema.

Yves-Marie Bercé, na pista de George Rudé, próximo de Hobsbawm, demonstra como o fenômeno dos levantes populares franceses no século XVII suscitou, dos contemporâneos, impressões que associavam os tumultos a uma espécie de doença coletiva. ${ }^{28}$ Multiplicaram-se incessantemente testemunhos mencionando espíritos doentes, crises de febre e frenesi. Falam de um povo irresponsável, ignorante e cego, que sucumbe ao impulso de qualquer inimigo sedicioso do Estado. ${ }^{29}$

O movimento das reformas católica ou protestante na Europa desde o século XVI tornou mais consistentes e efetivos os ataques habituais dos religiosos aos comportamentos populares identificados como paganismo ou licenciosidade. Dos muitos decretos emanados do Concílio de Trento, alguns condenavam a licenciosidade das festas regadas a tumulto e muita bebida,

\footnotetext{
${ }^{27}$ VILHENA, L. S. Recopilação de notícias soteropolitanas e brasílicas, livro II. Salvador: Imprensa Oficial do Estado, 1921, p. 445. O recurso à detratação do protesto popular na Conjuração Baiana aparece tratado em VALIM, Patrícia. Da sedição dos mulatos à Conjuração Baiana de 1798: a construção de uma memória histórica. Dissertação de mestrado, Universidade de São Paulo, 2007, especialmente capítulos 1 e 2.

${ }^{28}$ BERCÉ, Yves-Marie. Histoire des croquants. Étude des soulèvements populaires au XVIIe. siècle dans le sud-ouest de la France, tomo I. Genebra: Librairie Droz, 1974; RUDÉ, George. A multidão na historia; estudo dos movimentos populares na França e na Inglaterra, 1730-1848. São Paulo: Campus, 1991; HOBSBAWM, Eric John. Rebeldes primitivos: estudos sobre formas arcaicas de movimentos sociais nos séculos XIX e XX. São Paulo: Zahar Editores, 1970.

${ }^{29}$ BERCÉ, Yves-Marie. Histoire des croquants. Étude des soulèvements populaires au XVIIe. siècle dans le sud-ouest de la France, op. cit., 1974, p. 662.
} 
rev. hist. (São Paulo), n.176, a03416, 2017 http://dx.doi.org/10.11606/issn.2316-9141.rh.2017.114859
Luciano Raposo de Almeida Figueiredo

A linguagem da embriaguez: cachaça e álcool no vocabulário político das rebeliōes na América portuguesa

servindo como medidas ostensivas para conter os excessos provocados com as tavernas. ${ }^{30}$

A literatura política não economiza nas invectivas contra a plebe. Suas qualidades eram a violência, a credulidade, a volubilidade e a inconstância. Gabriel Naudé, autor de Considerações políticas sobre golpes de estado (1661) e colaborador de Mazarino, sublinha com palavras duras os atributos do povo:

aprovar e desaprovar ao mesmo tempo, correr de um extremo ao outro, acreditar levianamente, revoltar-se subitamente, rosnar e murmurar constantemente: em suma, tudo o que pensa não passa de futilidade, tudo o que diz é falso e absurdo, o que condena é bom, o que aprova é mau, o que elogia é infame e o que faz e empreende não passa de mera loucura. ${ }^{31}$

O erudito conde de Assumar esposa valores semelhantes ao redigir o Discurso histórico e político..., texto de reação à violência empregada com um dos líderes dos amotinados de Vila Rica. Quando expõe o modo de se formarem os motins com participação popular, "que por seu gosto sustenta o tumulto", redige trecho lapidar:

Tal é a natureza do vulgo, que para se alegrar e folgar com o seu próprio mal, basta ser novidade e sem-razão, porque tem, como por hombridade e capricho, seguir tudo o que vem contra a razão, contra a piedade, e contra o agradecimento (...); pois se não pode negar que não há quem se entenda com o povo, porque ao mesmo tempo se enfada da paz e aborrece as perturbações; se vive oprimido, rompem queixas, e se logra descanso, brota em desordens; suas próprias felicidades o cansam; não sabe o que é prosperidade se o não ocupa a desgraça; não conhece as posses da dita, menos que o cerquem os apertos da miséria. ${ }^{32}$

Tais desqualificações desses segmentos sociais têm outra origem, na avaliação de Arlette Farge, historiadora francesa das mais inspiradas. Elas decorrem do "caráter emotivo de suas reações". ${ }^{33}$ Diz a autora que "a emotividade

\footnotetext{
${ }^{30}$ BURKE, Peter. Cultura popular na Idade Moderna. São Paulo: Companhia das Letras, 2012, p. 243-4. O autor descreve vasto painel de transgressões para ilustrar o processo de reforma da cultura popular. Ver especialmente o capítulo 8. A vitória da quaresma: a reforma da cultura popular, p. 231-265.

${ }^{31}$ VILLARI, Rosario. O rebelde. In: VILLARI, Rosario (dir.). O homem barroco. Tradução de Maria Jorge V. de Figueiredo. Lisboa: Presença, 1995, p. 95-114, p. 113.

${ }^{32}$ ASSUMAR, conde de. Discurso histórico e político sobre a sublevação que nas Minas houve no ano de 1720. Estudo crítico, estabelecimento do texto e notas de Laura de Mello e Souza. Belo Horizonte: Fundação João Pinheiro, CEHC, 1994, p. 84.

${ }^{33}$ FARGE, Arlete. Lugares para a história. Tradução de Fernando Scheibe. Belo Horizonte: Autêntica, 2011, especialmente "As disposições emotivas dos súditos do rei", p. 90-94; p. 90.
} 
popular é um pulso que bate rápido demais e que é preciso vigiar", razão pela qual forma-se na época a "crença na animalidade perigosa das multidões" que sublinhava "o desregramento de seus atos e de seus pensamentos". Tratava-se enfim, segundo ela, de "uma população presa da emoção [que] tem mais a ver com a animalidade do que com uma racionalidade qualquer" ${ }^{34}$

Acompanhando a fúria coletiva ou, se preferirmos, a emoção popular, a detratação adicional de embriaguez esteve sempre presente no julgamento das massas. ${ }^{35}$ Ela seria evocada algum tempo mais tarde por autores surpreendidos pelas multidões ensandecidas na Europa do Oitocentos. A fixação da psicologia da multidão aproximada da fúria enlouquecida e patológica evoca mais uma vez a embriaguez de "vários milhões de selvagens" que deixam suas paixões brutais irromperem para abrir caminho para a Revolução Francesa. Segundo estudo de Dominique Julia, esta é a perspectiva de Hippolyte Taine em seu livro Origens da França contemporânea de 1858, para quem o tumulto de "loucos perigosos" resulta de "mulheres que têm fome e homens que beberam". ${ }^{36}$

O papel da ebriedade foi evocado como categoria central para definir o caráter das multidões que entravam em cena no decorrer do século XIX e serviu para formulação de juízos conservadores sobre as fraturas sociais do final do século XVIII. ${ }^{37}$ Taine caracteriza a razão não como um dom inato, mas como "um estado de equilíbrio instável, que depende do estado não menos instável do cérebro, dos nervos, do sangue e do estomago" ${ }^{38}$

Em tais perspectivas, a noção de intemperança, ao embalar as emoções, a fúria e a instabilidade, adere à concepção dos motins na ótica dos grupos dominantes. Colaborou ainda para cristalizar certa "visão espasmódica da

\footnotetext{
${ }^{34}$ FARGE, Arlete. Lugares para a história, op. cit., especialmente "As disposições emotivas dos súditos do rei", p. 90-94; p. 90.

${ }^{35}$ Como não poderia deixar de ser, o tema não escapou do exame de E. P. Thompson, quando analisa a associação entre relaxamento moral e sedição política na Inglaterra. THOMPSON, E. P. A formação da classe operária inglesa, vol. 2. Rio de Janeiro: Paz e Terra, 1987, p 293.

${ }^{36}$ JULIA, Dominique. A violência das multidões: é possível elucidar o desumano? In: BOUTIER, Jean \& JULIA, Dominique (org.). Passados recompostos. Campos e canteiros da história. Rio de Janeiro: Editora da UFRJ/Editora FGV, 1998, p. 217-232, p. 218.

${ }^{37}$ Os discursos contra a embriaguez associam-se à afirmação do comportamento burguês que condena os excessos da nobreza e do povo com a bebida e a comida. A ideia é apresentada também por FERNANDES, João Azevedo. Selvagens bebedeiras: álcool, embriaguez e contatos culturais no Brasil colonial (séculos XVI-XVII). São Paulo: Alameda, 2011, p. 27.

${ }^{38}$ JULIA, Dominique. A violência das multidões: é possível elucidar o desumano?, op. cit., 1998, p. 217-232, p. 218.
} 
Luciano Raposo de Almeida Figueiredo

A linguagem da embriaguez: cachaça e álcool no vocabulário político das rebeliöes na América portuguesa

história popular" (expressão que E. P. Thompson empregou para defender o papel do povo como agente histórico) e para endossar leituras conservadoras que percebiam os protestos populares como reações descontroladas destituídas de sentido. ${ }^{39}$

A linguagem da embriaguez é prescritiva ao sublinhar a perspectiva que toma a rebelião de homens e mulheres da arraia miúda como um movimento desordenado e fora da ordem natural das coisas, pois deles só se pode esperar obediência. Homens e mulheres incapazes para a vida política encetam atitudes que só poderiam ser compreendidas fora do estado de consciência, ou da razão.

\section{O ideal moderado dos príncipes}

Se às multidões se atribuía o excesso, dos reis desejava-se a temperança. O mundo luso-brasileiro também pareceu orientar-se pelos parâmetros da condenação dos excessos, e um dos modelos de virtude era a conduta dos soberanos e das Cortes. A temperança recomendada aos príncipes por teólogos e moralistas desde a Idade Média se dirigia à gula, associada, mais do que qualquer outro exagero, à luxúria e à sensualidade. A insistência permaneceria no século XVI em que a literatura normativa dedicada à educação do príncipe valorizava o controle das paixões e a temperança. ${ }^{40}$

A mesma preocupação valia para o consumo de bebidas, especialmente o vinho, líquido por excelência da Corte em Portugal. ${ }^{41}$ Seu consumo desregrado, contudo, era um perigo iminente que motivava recomendações dos Espelhos de Príncipes, elenco das diretrizes que um bom príncipe deveria perseguir. $^{42}$ Alfonso X de Castela, el Sabio, em seu extenso código legal Las

\footnotetext{
${ }^{39}$ THOMPSON, E. P. La economia "moral" de la multitud en la Inglaterra del siglo XVIII. In: Idem. Tradición, revuelta y consciencia de clase. Estudios sobre la crisis de la sociedade preindustrial. Barcelona: Editorial Crítica, 1979, p. 62-134; e THOMPSON, E. P. Costumes em comum. São Paulo: Companhia das Letras, 2000.

${ }^{40}$ BUESCU, Ana Isabel. À mesa do rei. Cultura alimentar e consumo no século XVI. In: SÁ, Isabel dos Guimarães \& FÉRNANDEZ, Máximo García (dir.). Portas adentro. Comer, vestir e habitar na península Ibérica (séculos XVI-XIX). Valladolid; Universidad Valladolid: Impr. Um. de Coimbra, 2010, p. 19-46, p. 34-35.

${ }^{41}$ Sobre o tema ver FERNANDES, João Azevedo. Selvagens bebedeiras: álcool, embriaguez e contatos culturais no Brasil colonial (séculos XVI-XVII), op. cit., 2011, "Portugal e a civilização do vinho", p. 109-123.

${ }^{42}$ BUESCU, Ana Isabel. À mesa do rei. Cultura alimentar e consumo no século XVI, op. cit., 2010, p. 19-46; p. 36-37. Sobre os Espelhos de Príncipes ver MONTEIRO, Rodrigo Bentes. O rei no espelho. A monarquia portuguesa e a colonização da América, 1640-1720. São Paulo: Editora Hucitec, 2002.
} 
siete partidas... sugeria, no século XIII, uma saída ardilosa: estimular seus cortesãos a beberem sem freios, enquanto o soberano nada tomava, "porque então", aconselhava o rei sagaz, "poderás muitos segredos entender e ouvir". ${ }^{43}$

Outros Espelhos de Príncipes não demonstravam tanta tolerância. No Principe perfecto y ministros aiustados. Documentos políticos y morales, de 1662, o padre da Companhia de Jesus, qualificador da Inquisição e leitor de teologia e sagradas escrituras em Salamanca, Andrés Mendo, dramatiza o mau exemplo de certo rei da Pérsia que bebia em demasia,

con que no quedava capaz para el despacho: enojosse de oyr esta verdad, y le mando traer delante de si un hijo, à quien despues de aver bebido, como folia, apuntò con una saeta [seta] el corazon, y le traspasò con ella a los ojos de su padre, diziendole: Que mirasse, como el vino le dexaba la vista despejada, e la mano segura. Barbara accion. Execrable ódio de la verdad!44, escreveu o clérigo.

O consumo etílico é o anátema do mau príncipe. Erasmo, em A educação de um príncipe cristão, alertaria para o comportamento de "bebedor frequente" dentre as graves condutas dos soberanos pobres de caráter, junto a outras como a de ser "um habilidoso jogador de dados, (...) um impiedoso destruidor da decência, o enganador mais astuto, um saqueador insaciável, um homem coberto de perjúrio, sacrilégio, traição e todos os tipos de crime". ${ }^{45}$ Em uma época cuja inspiração bebia nas prescrições de Aristóteles e Platão, a baliza é moral. Tomava-se então a defesa da ética clássica antiga da moderação no beber e em todos os atos da vida. ${ }^{46}$

${ }^{43}$ BUESCU, Ana Isabel. À mesa do rei. Cultura alimentar e consumo no século XVI, op. cit., 2010, p. 19-46; p. 36-37.

${ }^{44}$ MENDOS, Andrés. Principe perfecto $y$ ministros aiustados. Documentos politicos, $y$ morales, livro LXIX. Lyon: Horacio Boissat y George Remeus, 1662, p. 48.

${ }^{45}$ ROTERDÃ, Erasmo de. A educação de um príncipe cristão. In: Conselho aos governantes. Brasília: Conselho Editorial do Senado Federal, 2003 [1516], p. 314. (Coleção Clássicos da Política)

${ }^{46}$ CARNEIRO, Henrique. Bebida, abstinência e temperança na história antiga e moderna. São Paulo: Editora Senac, 2010, p. 153. Para um histórico da temperança na cultura ocidental, ver também FERNANDES, João Azevedo. Do problema do álcool ao álcool como problema. In: Idem. Selvagens bebedeiras: álcool, embriaguez e contatos culturais no Brasil colonial (séculos XVI-XVII), op. cit., 2011, p. 20-36. 


\section{A bebedice dos negros}

Sob as vistas dos clérigos, das autoridades civis e dos senhores, a embriaguez se avizinhou das novas dinâmicas sociais que nasceram com a experiência de colonização na América portuguesa. A missionação e catequese dos nativos, estabelecendo contatos culturais destes com os europeus, logo proporcionaram a condenação vigorosa das "borracheiras" indígenas. ${ }^{47}$

A presença crescente de africanos introduziria outras exigências. Ao lado dos engenhos de açúcar que se espalharam velozes pela geografia americana multiplicaram-se, desde o século XVII, alambiques que potencializam o grau do mel da cana e de seu caldo. Fonte de calorias para escravos, "água de fogo" para equilibrar os humores do corpo, capital de reserva para que as finanças dos senhores de engenhos aguentassem os repiques caprichosos do preço internacional do açúcar, a "aguardente da terra" se massificou quando passou a servir ao tráfico, especialmente na região de Angola. ${ }^{48}$

No cotidiano colonial, o consumo abusivo da bebida pelos escravos podia gerar situações incontroláveis, acionando o temor social e as armas da teologia moral. Nos engenhos, atento aos riscos da embriaguez dos escravos, o jesuíta Antonil desaconselhava que destilassem a aguardente do mel que escorria dos pães de açúcar, mais forte que a cachaça, oriunda do líquido formado pela espuma do caldo que é colocado para ferver, "para não ter uma contínua desinquietação na senzala dos negros, e que os seus escravos e escravas não sejam com a aguardente mais borrachos do que os faz a cachaça".49

Uma provisão do governador geral do Brasil na Bahia, de 9 de novembro de 1639, chegou a proibir a produção de aguardente e vinho de mel de cana na colônia portuguesa, justificando a medida em razão dos prejuízos que causa ao comércio e à arrecadação do vinho português. Havia porém inconvenientes mais sérios. A existência dos "alambiques e oficinas de aguardentes" era prejudicial "ao povo", pois o uso da cachaça motivava "muitas mortes nos escravos e furtos aos senhores", atestavam algumas des-

\footnotetext{
47 O tema foi tratado de maneira exemplar na obra de FERNANDES, João Azevedo. Selvagens bebedeiras: álcool, embriaguez e contatos culturais no Brasil colonial (séculos XVI-XVII), op. cit., 2011.

${ }^{48}$ CURTO, José C. Álcool e escravos. O comércio luso-brasileiro do álcool em Mpinda, Luanda e Benguela durante o tráfico atlântico de escravos (c. 1480-1830) e o seu impacto nas sociedades da África central ocidental. Tradução de Márcia Lameirinhas. Revisão científica de Alfredo Margarido. Portugal: Editora Vulgata, 2002, p. 95.

${ }^{49}$ ANTONIL, André J. Cultura e opulência do Brasil. Belo Horizonte: Itatiaia, 1982, p. 133.
} 
sas leis. ${ }^{50}$ Buscando efeitos moralizantes, a associação entre a bebedeira de negros e a perturbação da ordem pública ganha expressão nas sátiras que circulam na Bahia do século XVII em que negros figuram "enfrascados (...)/ não de pólvora atacados,/calcados de jeribita".51

O temor com os efeitos do álcool se espalharia pelo território, suscitando medidas de controle sem grandes efeitos. O alto consumo de aguardente pelos escravos em Minas Gerais provocou nas autoridades portuguesas tentativas para limitar a multiplicação de engenhos que fabricassem o gênero. Ainda que ferisse as expectativas de arrecadação fiscal, o acesso à bebida sugeria perigo social e político uma vez que o consumo desbragado animava rebeliões e violências entre os cativos, seus maiores consumidores. ${ }^{52} \mathrm{O}$ desembargador Teixeira Coelho se junta ao coro e sustenta em sua instrução que os engenhos dedicados a destilar aguardente prejudicavam o sossego público, causando desordem "pela bebedice dos negros". ${ }^{53} \mathrm{E}$, longe dos engenhos senhoriais, a aguardente alcançou os territórios de resistência, como nos quilombos mineiros onde se organizaram alambiques para não faltar cachaça ${ }^{54}$

A taberna é outro local de perigo iminente e não faltaram medidas para regular seu funcionamento, controlar o público que a frequentava e vigiar as tramas que ali eram urdidas pelos grupos populares. Na América espanhola, especialmente no México, viviam-se tensões da mesma natureza, como analisou William B. Taylor em seu instigante livro Drinking, homicide and rebellion in colonial Mexican villages. Em Nova York, as tabernas seriam igualmente pontos de encontros suspeitos por onde circulavam soldados,

\footnotetext{
${ }^{50}$ Publicado em ACCIOLI, I. \& AMARAL, B. Memória histórica e política da província da Bahia, vol. 2. Salvador: IOE, 1931, p. 255-56.

${ }^{51}$ HANSEN, João Adolfo. A sátira e o engenho - Gregório de Matos e a Bahia do século XVII. São Paulo: Cia. das Letras/Secretaria Estadual de Cultura, 1989, p. 325.

${ }^{52}$ As relações entre a criação de engenhos de açúcar e aguardente e perigo social em Minas Gerais no século XVIII foram discutidas por SILVA, Flávio Marcus da. Subsistência e poder. A política do abastecimento alimentar nas Minas setecentistas. Belo Horizonte: Editora da UFMG, 2008 (ver especialmente o capítulo 7, "a política dos engenhos"). Julita Scarano defende que "a aguardente vista como perigosa é a feita de cana, e aquela do Reino era considerada de valor". SCARANO, Julita. Cotidiano e solidariedade. Vida diária da gente de cor nas Minas Gerais, século XVIII. São Paulo: Brasiliense, 1994, p. 63.

53 COELHO, José João Teixeira. Instrução para o governo da capitania de Minas Gerais (1782). Organização, transcrição e textos introdutórios de Caio Cesar Boschi. Belo Horizonte: Secretaria de Estado da Cultura; Arquivo Público Mineiro; IHGB, 2007.

${ }^{54}$ FLORENTINO, Manolo \& AMANTINO, Márcia. Fugas, quilombos e fujões nas Américas (séculos XVI-XIX). Análise Social, n. 203, Lisboa, 2012, p. 194.
} 
marujos e escravos que conspiravam nos idos de 1741, enquanto o Atlântico fervilhava de rebeliões. ${ }^{55}$

Ou mesmo longe daqui. No Velho Mundo, guardando distinções corporativas que separam as funções das tabernas e dos bares, em Paris, conforme Daniel Roche, o bar - e mesmo a "ignóbil taberna", segundo Michelet - desde o século XIV vai merecendo "uma coloração criminal". À medida que se ampliam os controles policiais sobre a movimentação na cidade, o autor identifica, dentre as dimensões do perigo que os bares representam quando do "formigamento das escórias populares", sua ligação com as formas diversas do protesto, inclusive identificando esses locais com a preparação das rebeliões. ${ }^{56}$ Em síntese, "rebeliões e revoltas, tudo remete ao bar". ${ }^{57}$

Na América portuguesa, especialmente na região montanhosa das $\mathrm{Mi}$ nas Gerais durante a época da mineração, foi enorme o temor dessa associação entre tabernas, vendas ou rancho e revoltas. A intensa legislação que procurou regular o funcionamento das vendas, quase sempre nas mãos de mulheres forras ou escravas, não perdia de vista o risco iminente trazido pela bebida nestes ambientes. Não raro mencionavam-se violências que levavam a ferimentos e mortes de escravos, condutas imorais disseminadas por entre os clientes de baixa extração e as conspirações que se tramavam por ali. ${ }^{58}$

Em uma ação mais incisiva e moralizante, a perseguição à bebedeira se torna também alvo da Igreja. Ao menos assim se passa em Minas Gerais setecentista, quando clérigos não tiram o olho dos ébrios contumazes, multando-os e cobrindo-os de advertências em diversas visitas episcopais que percorreram o território. Na freguesia de Nossa Senhora da Conceição da Vila do Príncipe, João Gonçalves recebeu, em 1753, notificação “pela culpa de embriaguez", recomendando o padre que "de todo se apartasse de tão pernicioso vício, com que atualmente se acha privando-se do juízo". Era a segunda vez que recebia a mesma multa. No mesmo local e ano, o carpinteiro Francisco Luiz Carapina, morador no Itambé, foi notificado pela culpa de embriaguez

${ }^{5}$ LINEBAUGH, Peter $\mathcal{E}$ REDIKER, Marcus. A hidra de muitas cabeças: marinheiros, escravos, plebeus e a história oculta do Atlântico revolucionário. São Paulo: Cia. das Letras, 2008, p. 192-197. Agradeço a João Fernandes Azevedo a lembrança desta obra.

${ }^{56}$ ROCHE, Daniel. O povo de Paris. Ensaio sobre a cultura popular no século XVIII. Tradução de Antônio de Pádua Danesi. São Paulo: Edusp, 2004, p. 336.

${ }^{57}$ ROCHE, Daniel. O povo de Paris. Ensaio sobre a cultura popular no século XVIII, op. cit., 2004, p. 326.

${ }^{58}$ Um apanhado mais completo sobre as autuações de comerciantes e consumidores de aguardente em Minas encontra-se na dissertação de SILVA, Valquiria. F. D. De cabeça de porco à bebida de negro: um estudo sobre a produção e o consumo da aguardente nas Minas Gerais no século XVIII. Dissertação de mestrado em História, UFMG, Belo Horizonte, 2015. 
e advertido "que de todo se apartasse do costume que tinha de se tomar bebidas privando-se com elas do juízo no que cometia ofensas a Deus".59

Sob esse ponto de vista, "o beber em demasia" configurava uma falha de natureza religiosa, um pecado. O beberrão contumaz não realizava apenas um ato contrário à boa ordem civilizacional, mas cometia uma falha grave enquanto membro da comunidade cristã". ${ }^{60}$ A perda do autocontrole individual impedia a introspecção necessária à consciência cristã para se alcançar a salvação. ${ }^{61}$

O consumo exagerado da bebida foi alegação utilizada para desqualificar a população escrava em outras instâncias de julgamento, atrapalhando até o projeto de conquista da alforria. Certo crioulo que atuava no arraial de Paracatu luta na Justiça com seu proprietário que resiste em alforriá-lo, alegando que não recebeu toda a quantia tratada. No processo judicial, o senhor desqualifica Cosme Teixeira Pinto em virtude de sua afeição ao álcool. Dizia: "tudo quanto ganhava era pouco para o gastar em se vestir e se emborrachar". Uma das testemunhas não alivia a imagem de Cosme que "na verdade era bêbado", ainda que observasse: "não que caísse na rua porém sempre andava a baforar pela boca ou mão cheiro de cachaça ou aguardente de cana". ${ }^{62}$

\section{Águas rebeldes}

Mas as coisas mudavam muito de figura quando se tratava de enfrentar a máquina do rei através de protestos armados coletivos. A embriaguez, como vimos, foi uma das tópicas adotadas para demarcar tais situações estranhas na ordem natural das coisas.

A linguagem que nos interessa esgrima juízos moralizantes e virtudes, despejada contra o comportamento que escapa da norma política e das hierarquias sociais que definiam a ordem de uma república idealizada com base na harmonia e na concórdia.

\footnotetext{
${ }^{59}$ Arquivo Eclesiástico da Arquidiocese de Diamantina. Devassa de 1753, f 83. (Agradeço a Júnia Furtado pela cessão desse documento). Além das visitas pastorais fisgando bebedeiras, o consumo de vinho e de cachaça esteve largamente presente nos encontros amorosos homoeróticos em Portugal e na colônia, flagrados nos registros cuidadosos do Santo Ofício, como demonstrou MOTT, Luiz. In vino veritas: vinho e aguardente no cotidiano dos sodomitas luso-brasileiros à época da Inquisição, Topoi 6.10, 2005, p. 9-28.

${ }^{60}$ FERNANDES, João Azevedo. Selvagens bebedeiras..., op. cit., 2011, p. 163.

${ }^{61}$ Ibidem, p. 164.

${ }^{62} \mathrm{O}$ caso é discutido por PAIVA, Eduardo França. Escravos e libertos nas Minas Gerais do século XVIII. Estratégias de resistência através dos testamentos. São Paulo: Annablume, 1995, p. 84-86.
} 
Na América, a elaboração de juízos contra a prática do protesto armado com participação da plebe absorveu os predicados da bebida popular, sorvida por escravos e luso-brasileiros pobres, e dissociada do vinho, apanágio dos homens de distinção. "Cachaça" ou "aguardente" reforçam a clivagem subalternizada desses movimentos, posto que lembravam bebidas de escravos e miseráveis, situados na baixíssima escala da ordem social. ${ }^{63}$

O exame da documentação colonial de variado feitio (administrativa, fiscal, epistolar, memorialística ou medicinal) em busca de referências ao designativo correspondente ao destilado da cana de açúcar sugere algo inquietante. Se o termo "aguardente" era empregado para situações associadas à economia e à fiscalidade, como na legislação a respeito do seu comércio, ou integrava registro mais erudito e formal conforme as circunstâncias, o uso da palavra "cachaça" parece preponderar quando apresentada em situações marcadas por tensões sociais, habitualmente envolvendo escravos, forros e a plebe rude. A hipótese pode ainda ser prematura e está longe de obedecer a uma regra, mas a frequência com que a distinção entre "cachaça" e "aguardente" costumava acompanhar a diferença entre os níveis sociais, desqualificando os grupos subalternos, é notável no vocabulário político. ${ }^{64}$

A metáfora alusiva ao uso desregrado de cachaça integrava a munição retórica que avivava as más qualidades da multidão assinalando socialmente a reprovação de suas reações. Seu uso foi sagaz na medida em que a menção ao consumo de bebidas alcoólicas plasmou seus efeitos aos do caráter atribuído a ela, instável, fugaz, destituído de um caminho claro e sem tenacidade. Multidão incerta como um corpo bêbado que cambaleia. Contudo, a desqualificação das revoltas com participação popular não é só

\footnotetext{
${ }^{65}$ Tecnicamente chegou a haver, nos primeiros séculos, uma distinção entre "cachaça" e "aguardente" (da terra) que foi aos poucos se desvanecendo. Ambas as designações referiam-se ao destilado da cana de açúcar, porém a "cachaça" era produzida a partir do mel que escorria das formas de barro em que descansava o açúcar, ao passo que a "aguardente" utilizava o caldo de cana.

${ }^{64}$ Em seu estudo sobre consumo da aguardente em Minas Gerais, Valquíria Silva pode notar uma percepção semelhante a respeito. Do total de dezenove "autos de achada" que investiga referentes à apreensão da bebida "a designação mais frequente, representando 50\% dos casos, foi a de cachaça o que, quando lida no conjunto da documentação, aponta para o fato de que o termo cachaça - mais do que a aguardente da terra e até mesmo a aguardente - apareceu, quase sempre, combinado aos negros, o que revela não só que o(a)s escravo(a)s e forro(a)s eram os que mais comumente vendiam essa bebida ilegalmente, como o mercado consumidor dos morros, majoritariamente formado pelos escravos nos serviços de mineração, era o seu maior consumidor." SILVA, Valquíria F. D. De cabeça de porco à bebida de negro: um estudo sobre a produção e o consumo da aguardente nas Minas Gerais no século XVIII, op. cit., 2015, p 163.
} 
retórica. Ao contrário do que se passa com as inquietações conduzidas pela elite social que, salvo exceções, sugeriam por parte das autoridades contemporização, também a violência dedicada aos grupos sociais das camadas inferiores deve ser exemplar, pois, como a certa altura lembrou Roger Chartier, também ela é necessária à ordenação do mundo. ${ }^{65}$ Soldados famintos, índios e mamelucos achacados, escravos lutando por autonomia mereceram a pena de enforcamento nas revoltas que mencionamos - como se passa em Salvador e Angola - assim como prisões e confiscos no sertão do São Francisco. ${ }^{66}$

O historiador italiano Rosario Villari demonstra em um ensaio de grande erudição e poder interpretativo como um certo tipo de revolta europeia no século XVII estabeleceu dignidade à figura do rebelde. Até ali ele esteve associado à imagem "do bandido comum, dos marginais (...), dos perversores das normas de comportamento universalmente reconhecidas e aceites". Ou ainda eram atributos dos sediciosos "orgulho, torpe ambição, desprezo pela coletividade, perfídia e negação das regras da honra (...)".67 Porém, desde as lutas envolvendo comunidades nacionais contra a tirania durante a crise do século XVII - seja ela espanhola, como na Catalunha e em Portugal, seja inglesa, como na Escócia -, operando de maneira diferente da oposição aristocrática tradicional (do "velho e anacrônico rebeldismo nobre"), os rebeldes realizam a fusão entre a utilidade pública e o interesse geral "constituindo a base de uma real e nova união política na crise revolucionária". 68 Para esse rebelde dotado de dignidade Villari elabora a expressão "democratic gentleman". ${ }^{9}$

Na América portuguesa, a operação discursiva que se verificou com as revoltas até o último quartel do século XVIII tendeu a ser oposta, seja porque as elites coloniais, quando rebeldes, eram incapazes de identificar tirania na figura régia, seja porque aos grupos populares era inadmissível a atuação na vida política.

Mas o jogo desse uso depreciativo da cachaça, ou da aguardente da terra, por vezes podia mudar, reafirmando sua relevância para o imaginário

\footnotetext{
${ }^{65}$ CHARTIER, Roger. A história cultural entre práticas e representações. Lisboa: Difel, 1990, cap. VII Cultura política e cultura popular no Antigo Regime, p. 209-212.

${ }^{66}$ Para uma análise da presença popular nos protestos do Brasil colonial ver RODRIGUES, Gefferson Ramos. Escravos, índios e soldados: povo, política e revoltas na América portuguesa do século XVIII (Pernambuco, Minas Gerais e Bahia). Tese de doutorado em História, Universidade Federal Fluminense, 2015.

${ }^{67}$ VILLARI, Rosario. O rebelde. In: VILLARI, Rosario (dir.). 0 homem barroco. Tradução de Maria Jorge V. de Figueiredo. Lisboa: Presença, 1995, p. 95-114, p. 108.

${ }^{68}$ VILLARI, Rosario. O rebelde, op. cit., 1995, p. 95-114, p. 111.

${ }^{69}$ VILLARI, Rosario. O rebelde, op. cit., 1995, p. 95-114, p. 111.
} 
político. Um dos movimentos mais radicais que tem lugar em Pernambuco, a Revolução de 1817, repleta de ideais revolucionários e autonomistas, inovou no tratamento atribuído à "aguardente da terra", homenageada até com o título de "patriota". Durante um brinde que celebrava as conquistas dos rebeldes, o padre João Ribeiro, diante do viajante francês Tollenare, sugeriu que bebessem aguardente de cana e não mais o vinho do Porto. ${ }^{70}$

Esse desfecho é de uma preciosa ironia. Desta vez, um luso-brasileiro demonstraria especial orgulho da bebida gentílica diante do estrangeiro, ao contrário do que se passou na anedota contada por Sérgio Buarque de Holanda.

\section{Referências bibliográficas}

ACCIOLI, I. E AMARAL, B. Memória histórica e política da província da Bahia. Salvador: IOE, 1931.

ALENCASTRO, Luiz Felipe de. O trato dos viventes. Formação do Brasil no Atlântico Sul, séculos XVI e XVII. São Paulo: Companhia das Letras, 2000.

ANASTASIA, Carla Maria Junho. Potentados e bandidos: os motins do São Francisco. Revista do Departamento de História da UFMG, n. 9, 1989, p. 74-85.

ANTONIL, André J. Cultura e opulência do Brasil. Belo Horizonte: Itatiaia, 1982.

ASSUMAR, conde de. Discurso histórico e político sobre a sublevação que nas Minas houve no ano de 1720. Estudo crítico, estabelecimento do texto e notas de Laura de Mello e Souza. Belo Horizonte: Fundação João Pinheiro, CEHC, 1994.

AVELAR, Lucas Endrigo Brunozi. A moderação em excesso: estudo sobre a história das bebidas na sociedade colonial. Dissertação em História, USP, 2010.

BERCÉ, Yves-Marie, Histoire des croquants. Étude des soulèvements populaires au XVIIe. siècle dans le sud-ouest de la France. Genebra: Librairie Droz, 1974.

BLUTEAU, Raphael. Vocabulario portuguez \& latino, vol. 4, p. 177. Disponível em: http:// www.brasiliana.usp.br. Acesso em: 24 de janeiro de 2014.

BUESCU, Ana Isabel, À mesa do rei. Cultura alimentar e consumo no século XVI. In: SÁ, Isabel dos Guimarães E FÉRNANDEZ, Máximo García (dir.). Portas

\footnotetext{
${ }^{70}$ FREYRE, Gilberto. O status social da cachaça. In: Idem. Prefácios desgarrados. Rio de Janeiro: Cátedra, 1978, p. 230. Anos mais tarde, no Recife, estala um motim de soldados em 1823 que toma conta da cidade. O líder, Pedro Pedroso, um capitão pardo que participara de 1817 e ocupava agora o posto de comandante das armas da província, foi flagrado em um ambiente animado nos arredores da cidade, conforme contou o próprio frei Caneca. Nesta festa, estava "comendo e bebendo numa palhoça rodeado de negros e negras - uma delas no seu colo. Ouvia alegremente as cantorias. Prosaicamente, teria então chamado as autoridades que por ali passavam para se juntarem a ele. No ato daquele insólito convite a donos de terra e gente, teria dito: - Sempre estimei muito esta cor, é a minha gente", escreveu o historiador CARVALHO, Marcus. Rumores e rebeliões: estratégias de resistência escrava no Recife, 1817-1848. Revista Tempo, n. 6, 1998.
} 
adentro. Comer, vestir e habitar na península Ibérica (séculos XVI-XIX). Valladolid; Un. Valladolid: Impr. Un. de Coimbra, 2010.

BURKE, Peter. Cultura popular na Idade Moderna. São Paulo: Companhia das Letras, 2012. CALMON, Pedro. A vida espantosa de Gregório de Matos. Rio de Janeiro: José Olympio, 1983.

CAMPOS, Maria Verônica. Governo dos mineiros. "De como meter as Minas numa moenda e beber-lhe o caldo dourado". 1603 a 1737. Tese de História, USP, São Paulo, 2002.

CARNEIRO, Henrique. Bebida, abstinência e temperança na história antiga e moderna. São Paulo: Editora Senac, 2010.

CARVALHO, Teófilo Feu de. Ementário da história de Minas; Felipe dos Santos na sedição de Vila Rica, 1720. Belo Horizonte, [s.d.].

Rumores e rebeliões: estratégias de resistência escrava no Recife, 18171848. Revista Tempo, n. 6, 1998.

CHARTIER, Roger. A história cultural entre práticas e representações. Lisboa: Difel, 1990, cap. VII - Cultura política e cultura popular no Antigo Regime.

COELHO, José João Teixeira. Instrução para o governo da capitania de Minas Gerais (1782). Organização, transcrição e textos introdutórios de Caio Cesar Boschi. Belo Horizonte: Secretaria de Estado da Cultura; Arquivo Publico Mineiro; IHGB, 2007.

COSTA, Luiz Monteiro. Na Bahia colonial. Apontamentos para a história militar da cidade do Salvador. Bahia: Livraria Progresso Ed., [s.d.]. (Coleção de Estudos Brasileiros, série Marajoara, 23)

CURTO, José C. Álcool e escravos. O comércio luso-brasileiro do álcool em Mpinda, Luanda e Benguela durante o tráfico atlântico de escravos (c. 1480-1830) e o seu impacto nas sociedades da África central ocidental. Tradução de Márcia Lameirinhas. Revisão científica de Alfredo Margarido. Portugal: Editora Vulgata, 2002.

FARGE, Arlete. Lugares para a história. Tradução de Fernando Scheibe. Belo Horizonte: Autêntica, 2011.

FERNANDES, João Azevedo. Selvagens bebedeiras: álcool, embriaguez e contatos culturais no Brasil colonial (séculos XVI-XVII). São Paulo: Alameda, 2011.

FLORENTINO, Manolo $\mathcal{E}$ AMANTINO, Márcia. Fugas, quilombos e fujões nas Américas (séculos XVI-XIX). Análise Social, n. 203, Lisboa, 2012.

FONSECA, Alexandre Torres. A revolta de Felipe dos Santos. In: RESENDE, Maria Efigênia Lage de (coord). História de Minas Gerais. As Minas setecentistas, vol 1. Belo Horizonte: Companhia do Tempo; Autêntica, 2007.

FREYRE, Gilberto. O status social da cachaça. In: Prefácios desgarrados. Rio de Janeiro: Cátedra, 1978.

HANSEN, João Adolfo. A sátira e o engenho - Gregório de Matos e a Bahia do século XVII. São Paulo: Cia. das Letras/Secretaria Estadual de Cultura, 1989.

HASKELL, A. B. "The affections of the people": Ideology and the politics of State building in colonial Virginia, 1607-1754. Baltimore: Johns Hopkins University, 2004.

HOBSBAWM, Eric John. Rebeldes primitivos: estudos sobre formas arcaicas de movimentos sociais nos séculos XIX e XX. São Paulo: Zahar Editores, 1970.

JULIA, Dominique. A violência das multidões: é possível elucidar o desumano? In: BOUTIER, Jean $\mathcal{E}$ JULIA, Dominique (org.). Passados recompostos. Campos e canteiros 
da história. Rio de Janeiro: Editora da UFRJ/Editora FGV, 1998, p. 217-232.

LINEBAUGH, Peter $\mathcal{E}$ REDIKER, Marcus. A hidra de muitas cabeças: marinheiros, escravos, plebeus e a história oculta do Atlântico revolucionário. São Paulo: Cia. das Letras, 2008.

MARTINS, Renato (org). Sergio Buarque de Holanda. Encontros. Rio de Janeiro: Azougue, 2009.

MATHIAS, Carlos Leonardo Kelmer. No exercício de atividades comerciais, na busca da governabilidade: d. Pedro de Almeida e sua rede de potentados nas minas do ouro durante as duas primeiras décadas do século XVIII. In: FRAGOSO, João L. R. et al. (org.). Conquistadores e negociantes. Rio de Janeiro: Civilização Brasileira, 2007.

MENDOS, Andrés. Principe perfecto y ministros aiustados. Documentos politicos y morales. Lyon: Horacio Boissat y George Remeus, 1662.

MONTEIRO, Rodrigo Bentes. O rei no espelho. A monarquia portuguesa e a colonização da América, 1640-1720. São Paulo: Editora Hucitec, 2002.

MORAES, Francisco Teixeira de. Relação histórica e política dos tumultos que sucederam na cidade de S. Luiz do Maranhão, .... [1692]. RIHGB, tomo 40, $1^{\mathrm{a}}$ parte.

MOTT, Luiz. In vino veritas: vinho e aguardente no cotidiano dos sodomitas luso-brasileiros à época da Inquisição. Topoi 6.10, 2005, p. 9-28.

OLIVEIRA, António de. Poder e oposição política em Portugal no período filipino, 1580-1640. Lisboa: Difel, 1991.

PAIVA, Eduardo França. Escravos e libertos nas Minas Gerais do século XVIII. Estratégias de resistência através dos testamentos. São Paulo: Annablume, 1995.

PARREIRA, Adriano. Dicionário glossográfico e toponímico da documentação sobre Angola. Séculos XV-XVII. Lisboa: Editorial Estampa, 1990.

PITTA, Sebastião da R. História da América portuguesa. Introdução e notas de Pedro Calmon. Belo Horizonte: Itatiaia; São Paulo: Edusp, 1976.

RAMINELLI, Ronald, Honras e malogros: trajetória da família Camarão, 16301730. In: VAINFAS, Ronaldo \& MONTEIRO, Rodrigo Bentes (org.). Império de várias faces. Relações de poder no mundo ibérico da Época Moderna. São Paulo: Editora Alameda, 2009.

ROCHE, Daniel, O povo de Paris. Ensaio sobre a cultura popular no século XVIII. Tradução de Antônio de Pádua Danesi. São Paulo: Edusp, 2004.

RODRIGUES, Gefferson Ramos. No sertão, a revolta: Grupos sociais e formas de contestação na América portuguesa, Minas Gerais - 1736. Niterói-Rio de Janeiro: UFF/Departamento de História, 2009.

Escravos, índios e soldados: povo, política e revoltas na América portuguesa do século XVIII (Pernambuco, Minas Gerais e Bahia). Tese de doutorado em História, Universidade Federal Fluminense, 2015.

ROTERDÃ, Erasmo de. A educação de um príncipe cristão [1516]. In: Conselho aos governantes. Brasília: Conselho Editorial do Senado Federal, 2003. (Coleção Clássicos da Política)

RUDÉ, George. A multidão na historia. Estudo dos movimentos populares na França e na Inglaterra, 1730-1848. São Paulo: Campus, 1991. 
SCARANO, Julita. Bebida alcoólica e sociedade colonial. In: JANCSÓ, István E KANTOR, Iris (org.). Festa: Cultura e sociabilidade na América portuguesa. São Paulo: Hucitec; Editora da Universidade de São Paulo; Fapesp; Imprensa, 2001.

SILVA, Antônio de Moraes. Diccionario da lingua portuguesa. Disponível em: http:// www.brasiliana.usp.br. Acesso em: 24 de janeiro de 2014.

SILVA, Flávio Marcus da. Subsistência e poder. A política do abastecimento alimentar nas Minas setecentistas. Belo Horizonte: Editora da UFMG, 2008.

SILVA, Francisco Ribeiro da. Absolutismo esclarecido e intervenção popular. Os motins do Porto de 1757. Lisboa: Imprensa Nacional-Casa da Moeda, 1990.

SILVA, Valquíria. F. D. De cabeça de porco à bebida de negro: um estudo sobre a produção e o consumo da aguardente nas Minas Gerais no século XVIII. Dissertação de mestrado em História, UFMG, Belo Horizonte, 2015.

SOUZA, Laura de Mello e (org). História da vida privada no Brasil: cotidiano e vida privada na América portuguesa, vol. 1. São Paulo: Companhia das Letras, 1997.

THOMPSON, E. P. Costumes em comum. São Paulo: Companhia das Letras, 2000.

La economia "moral" de la multitud en la Inglaterra del siglo XVIII. In: Idem. Tradición, revuelta y consciencia de clase. Estudios sobre la crisis de la sociedade preindustrial. Barcelona: Editorial Crítica, 1979, p. 62-134. A formação da classe operária inglesa. Rio de Janeiro: Paz e Terra, 1987.

VALIM, Patrícia. Da sedição dos mulatos à Conjuração Baiana de 1798: a construção de uma memória histórica. Dissertação de mestrado em História, Universidade de São Paulo, 2007.

VENÂNCIO, Renato Pinto E CARNEIRO, Henrique (org.). Álcool e drogas na história do Brasil. Belo Horizonte-São Paulo: PUC Minas e Alameda, 2005.

VILHENA, L. S. Recopilação de notícias soteropolitanas e brasílicas. Salvador: Imprensa Oficial do Estado, 1921.

VILLARI, Rosario. O rebelde. In: VILLARI, Rosario (dir.). O homem barroco. Tradução de Maria Jorge V. de Figueiredo. Lisboa: Presença, 1995. 